\title{
Low-Resolution Mid-Infrared Reflection Analysis for Discernment of Contaminants in Seed Cotton
}

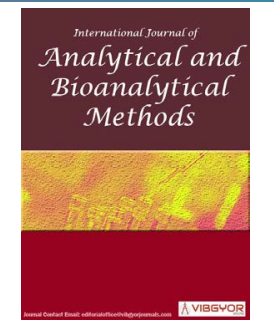

\section{Wenbin Jiang', Derek Whitelock², SE Hughs ${ }^{2}$ and Gary Rayson ${ }^{1 *}$}

${ }^{1}$ Department of Chemistry and Biochemistry, College of Arts and Sciences, New Mexico State University, USA ${ }^{2}$ USDA-ARS-SW Cotton Gin Research Lab, USA

\begin{abstract}
Contaminants mixed with cotton during harvesting and processing dramatically decreases its quality and economic value. A low resolution mid-infrared reflection instrument using four wavelengths $\left(3100,2900,2300\right.$, and $\left.1500 \mathrm{~cm}^{-1}\right)$ was designed and constructed to distinguish cotton samples from 16 common contaminants (e.g. plastic and grease). These wavelengths were identified from associated high-resolution FT-IR spectra using multivariable analysis (i.e. Principal Component Analysis, Cluster Analysis, and Multiple Curve Regression). Simulation of low resolution spectra was undertaken to demonstrate feasibility of these wavelengths. Cotton and contaminants samples were analyzed in triplicate using the resulting in-house constructed instrument. Contaminants were successfully differentiated from cotton in a $33.2 \mathrm{~mm}^{2}$ field of view with $100 \%$ accuracy. When mixed, limits of detection for positive identification of each contaminant was observed when the foreign material comprised between $11 \%$ and $60 \%$ of the field of view.
\end{abstract}

\section{Introduction}

Cotton is a very important natural fiber resource. Its production has an important impact on economies around the world. Higher cotton quality often increases its value and profitability [1]. However, contaminants mixed with cotton fiber during harvesting and processing dramatically decrease cotton's quality [2]. Cotton in the U.S. is widely harvested mechanically and packed using polymeric materials. Common contaminants in the cotton bale include both botanical components (e.g. leaf, stem) and synthetic materials (e.g. plastic bag, module cover) [3]. Identification and removal of contaminants in the cotton is a challenge. Although most large-sized cotton trash can be removed after ginning, this process can become more complicated due to the tendency of contaminants to be shredded to small fibers during processing $[3,4]$.

Currently, trade and regulatory offices and laboratories in the cotton industry use both the High Volume Instrument ( $\mathrm{HVI}^{\mathrm{TM}}$ ) and the Shirley Analyzer (SA) to measure cotton quality [5]. The $\mathrm{HVI}^{\mathrm{TM}}$ measures cotton length, strength, color, and trash content using visible imaging. It identifies the number of non-lint particles on a sample's surface and measures the surface area covered by nonlint particles [2,5]. The Shirley Analyzer (SA) is a

\footnotetext{
*Corresponding author: Gary D Rayson, Department of Chemistry and Biochemistry, College of Arts and Sciences, New Mexico State University, Las Cruces, NM 88003-8001, USA, P.O. Box 30001, Tel: 575-646-5839, Fax: 575-646-2649

Accepted: November 20, 2018; Published: November 22, 2018

Copyright: (C) 2018 Jiang W, et al. This is an open-access article distributed under the terms of the Creative Commons Attribution License, which permits unrestricted use, distribution, and reproduction in any medium, provided the original author and source are credited.

Jiang et al. Int J Analyt Bioanalyt Methods 2018, 1:001
} 
gravimetric technique to measure trash content using aero-mechanical methods to separate cotton fiber from trash. Although the $\mathrm{HVI}^{\mathrm{TM}}$ and the SA can measure some quality properties of cotton, they are limited to small cotton samples from each bale and lack specificity in the identification of different contaminant types in the cotton fiber $[6,7]$.

Many researchers have tried different optical technologies to distinguish various types of contaminants, such as imaging approaches, ultraviolet-visible spectroscopy (UV-VIS) and Infrared spectroscopy (IR). Xu, et al. developed an imaging system based on a color CCD camera using color, shape and size attributes of cotton $[7,8]$. While a classification accuracy $>95 \%$ in classifying different trash types was reported, the results indicated the color feature was more reliable because contaminate shape and size varied during cotton processing. The limitation of this method was the prohibitive processing time, rendering it impractical for general cotton industry implementation [7]. Alternatively, Fortier, et al. investigated the capability of UV-VIS and Fouriertransform near-infrared reflectance (FT-NIR) for identifying botanical cotton trash types [3]. These yielded respective rates of botanical trash identification of $67 \%$ and $98 \%$.

FT-NIR has also been widely used in cotton contaminants identification $[3,4,6,8]$. It is a rapid and accurate technique in identifying botanical cotton trash and synthetic materials. A NIR spectral library based on different botanical trash types has been generated enabling accurate cotton trash classification [5]. Fortier, et al. [6] also demonstrated an overall $98 \%$ accuracy in the botanical and synthetic material identification within pure cotton using a bench top FT-NIR instrument. Similarly, Himmelsbach, et al. successfully used

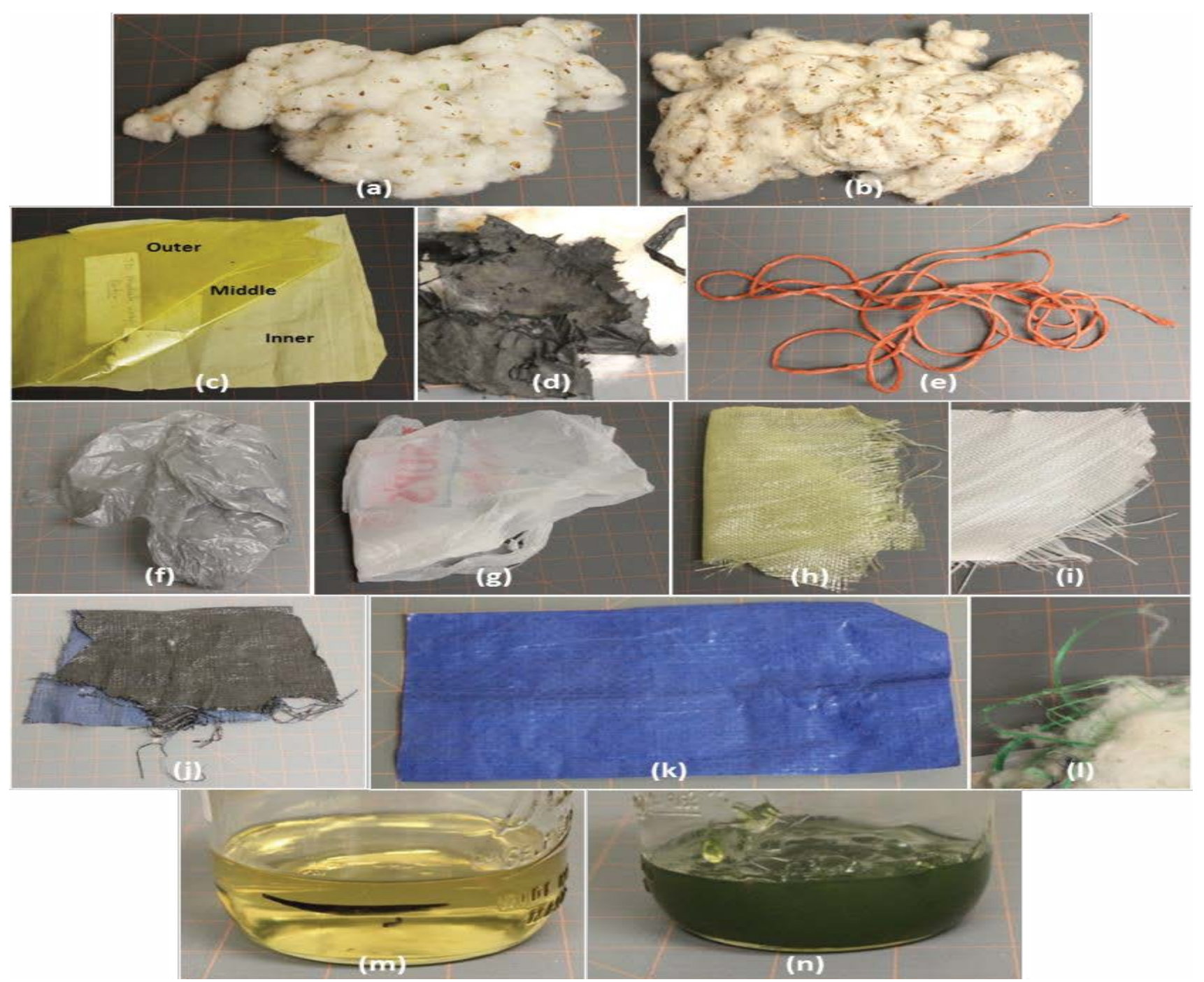

Figure 1: Samples analyzed in this research (The sample types are shown in Table 1). 
a FT-IR instrument with an Attenuated Total Reflectance (ATR) accessory to identify cotton botanical trash and synthetic materials [9]. The limitations of both FT-NIR and FT-IR have included the need of commercial instrumentation which can be prohibitively expensive. Samples must be collected and analyzed in the laboratory which is not conducive to their use in a processing facility $[10,11]$.

The ability to accurately identify individual contaminants in cotton fiber at the ginning facility would greatly improve both the efficiency of contaminant removal and resulting fabric production quality [12]. Each of the techniques currently used to discern contaminates within seed cotton prior to ginning requires expensive instrumentation, off-site processing, or both. The goal of this work was to construct an inexpensive low resolution (only four specific wavelength regions) mid-infrared reflectance instrument to distinguish cotton fibers from synthetic materials. Ultimately, it could be applied to routine analysis within a ginning facility. In this work, FT-IR spectra were collected from a collection of common contaminates and those spectral regions enabling contaminate discernment were identified using chemometric tools. The feasibility of broad bandpass filters for each region was tested by generating simulated reflectance spectra using higher resolution FT-IR data. A reflection instrument was then design and constructed for collection of such low-resolution spectra for both upland and pima cotton samples with each of the same common contaminates. An algorithm was developed that enabled contaminate discernment using these low-resolution spectra. Limits of contaminate detection were then determined using this instrument.

\section{Materials and Methods}

\section{Sample treatment and data analysis}

Cotton samples (upland and pima) and common contaminants are shown in Figure 1 for clarification of each material analyzed. These are further described in Table 1 with reference sample numbers used throughout the study. Each of these samples was initially analyzed in triplicate using a commercial infrared spectrometer (Nicolet is 10 FT-IR, Thermo Fisher, CA) with an attenuated total reflectance (ATR) sampling accessory. All spectra were collected using $1.0 \mathrm{~cm}^{-1}$ resolution and recorded as absorbance (i.e., - $\log ($ reflectance) ) as a function of wavenumber from 400 to $4000 \mathrm{~cm}^{-1}$. Representative spectra from a sample of cotton and each of five of the potential contaminates are shown in Figure 2. It should be noted that names used for each material are those commonly used within the cotton industry for clarity.

Principal component analysis (PCA) was applied to the resulting 54 spectra. This indicated $95.18 \%$ of the variance in the sample spectra could be described using five principal components. For illustration purposes, scores for the first three principal components (comprising $88.69 \%$ of the total variance) are shown in Figure 3a. Because five PCs were required to account for $>95 \%$ of the variance in the spectra, Cluster analysis (CA) was

Table 1: Samples analyzed by FT-IR in this study (The letters correspond to Figure 1. The numbers correspond to Figure 3a).

\begin{tabular}{|c|c|c|c|c|c|}
\hline Number & Sample names & Component & Number & Sample names & Component \\
\hline a (43-45) & Upland cotton & Cellulose & a (46-48) & Upland cotton stem & Cellulose \\
\hline b (34-36) & Pima cotton & Cellulose & b (37-39) & Pima cotton stem & Cellulose \\
\hline c (25-27) & JD module wrap outer & Polyethylene & c (22-24) & $\begin{array}{l}\text { JD module wrap } \\
\text { middle }\end{array}$ & Polyethylene \\
\hline c (19-21) & JD module wrap inner & Polyethylene & $d(4-6)$ & Black plastic & Polyethylene \\
\hline e $(1-3)$ & Bale twine & Polypropylene & $f(10-12)$ & Colored shopping bag & $\begin{array}{l}\text { High-density } \\
\text { polyethylene }\end{array}$ \\
\hline$g(52-54)$ & White shopping bag & $\begin{array}{l}\text { High-density } \\
\text { polyethylene }\end{array}$ & $h(7-9)$ & Colored bale bag & $\begin{array}{l}\text { Woven } \\
\text { polypropylene }\end{array}$ \\
\hline i (49-51) & White bale bag & $\begin{array}{l}\text { Woven } \\
\text { polypropylene }\end{array}$ & j (31-33) & Old module tarp & $\begin{array}{l}\text { Woven } \\
\text { polypropylene }\end{array}$ \\
\hline k (28-30) & New module tarp & $\begin{array}{l}\text { Woven } \\
\text { polypropylene }\end{array}$ & I (13-15) & Hard green & $\begin{array}{l}\text { Polyethylene } \\
\text { terephthalate }\end{array}$ \\
\hline m (16-18) & Hydraulic oil & Petroleum oil & n (40-42) & Spindle grease & Lubricating oil \\
\hline
\end{tabular}




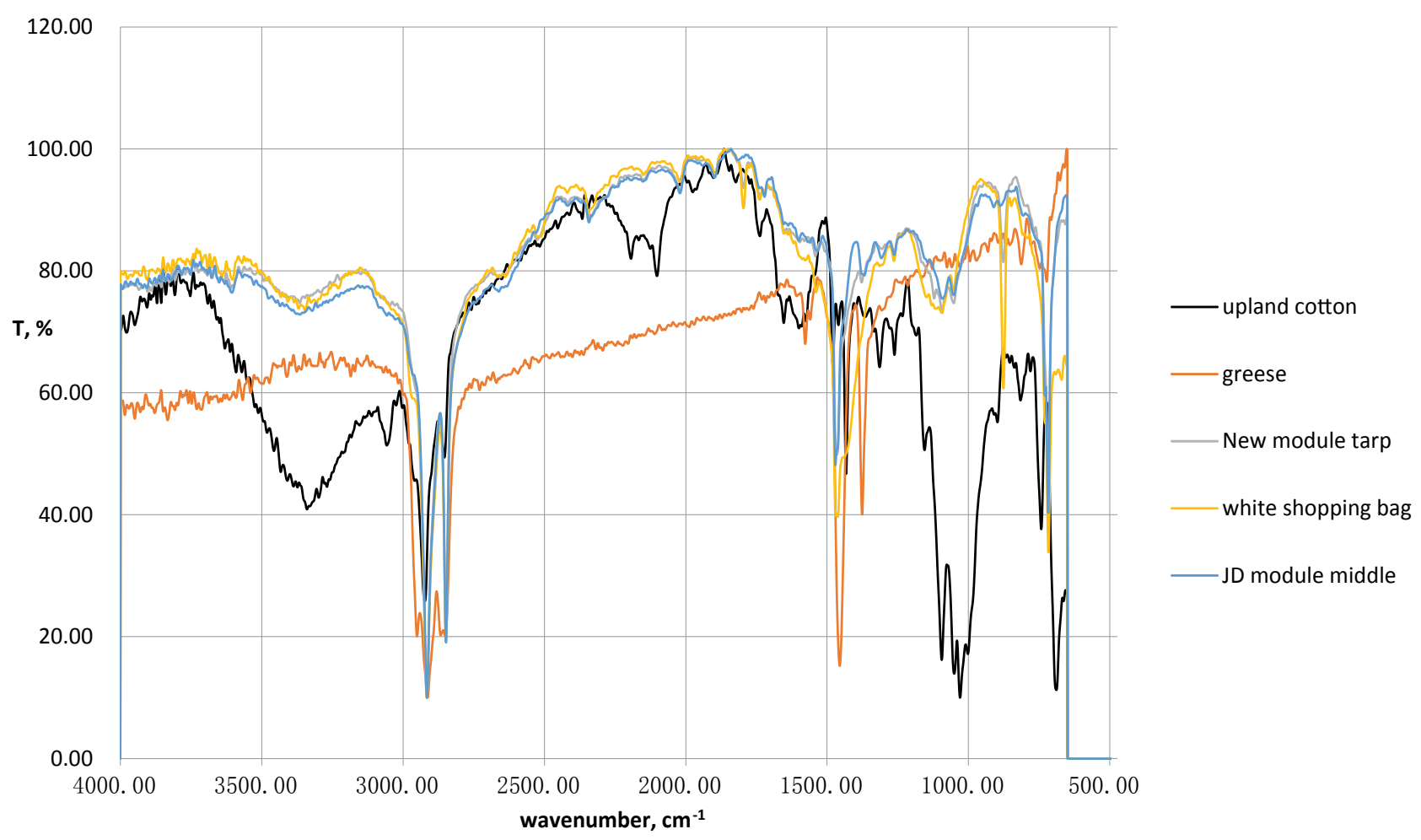

Figure 2: Fourier Transform Infrared spectra from a sample of upland cotton and four of the potential contaminants, grease, the new modules tarp material, a piece of the white shopping bag, and the JD module middle material (Figure 1).

undertaken to fully quantify separation of sample spectra projections into this 5-dimentional score space. The resulting dendrogram (Figure $3 b$ ) clearly illustrates the separation of materials into different clusters. For example, cotton samples are clustered together while the different polymeric materials were placed in separate clusters. IR spectra of the pure cotton fibers could not be further distinguished (i.e. Pima and upland). However, the measured spectral signatures were able to clearly distinguish cotton fibers from any of the common contaminants (Figure 1), including solid fiber and associated biological trash (e.g. plant stems), the objective of the present study. This demonstrated the ability to discern contaminate presence relative to cotton materials.

Although PCA of FT-IR reflectance spectra separated cotton material from extraneous materials, each resulting Principal Component is a purely mathematical parameter describing the data variance and is without any physical significance [13] and did not reveal spectral regions responsible for their separation. It should be also noted that while the eigenvectors resulting from PCA do not exhibit the shape of the spectra of the components, features can be strongly related to each component. An alternative statistical tool enabling discernment of the contribution of each variable (i.e. wavelength) to variance within a sample set is Multivariate Curve Regression (MCR). MCR enables extraction of those spectral features enabling distinction among a collection of components. Thus, the derived spectrum of each factor responsible for sample clustering can be ascertained from the total data set [14]. To discern which portion of the FT-IR spectra was responsible for distinguishing contaminants from cotton, MCR was applied to the FT-IR reflectance data. Absorption bands at 3100, 2900, 2300, 1500, and $1000 \mathrm{~cm}^{-1}$ were identified as characteristic features describing each component. These bands correspond to a wing on the $\mathrm{O}-\mathrm{H}$ stretching band $\left(3100 \mathrm{~cm}^{-1}\right), \mathrm{C}-\mathrm{H}$ stretching model $\left(2900 \mathrm{~cm}^{-1}\right)$, and C-C stretching $\left(2300 \mathrm{~cm}^{-1}\right)$ and bands at $1500 \mathrm{~cm}^{-1}$ and $1000 \mathrm{~cm}^{-1}$ indicative of vibrations within the fingerprint region of the spectrum (e.g., aliphatic $\mathrm{C}-\mathrm{H}$ bending and carbohydrate $\mathrm{C}-\mathrm{O}$ stretching). All spectra were compensated for atmospheric $\mathrm{CO}_{2}$ near $2300 \mathrm{~cm}^{-1}$ using the ATR accessory. It was then hypothesized measurement of reflectance at these four or five wavenumbers could be sufficient for contaminant discernment. 


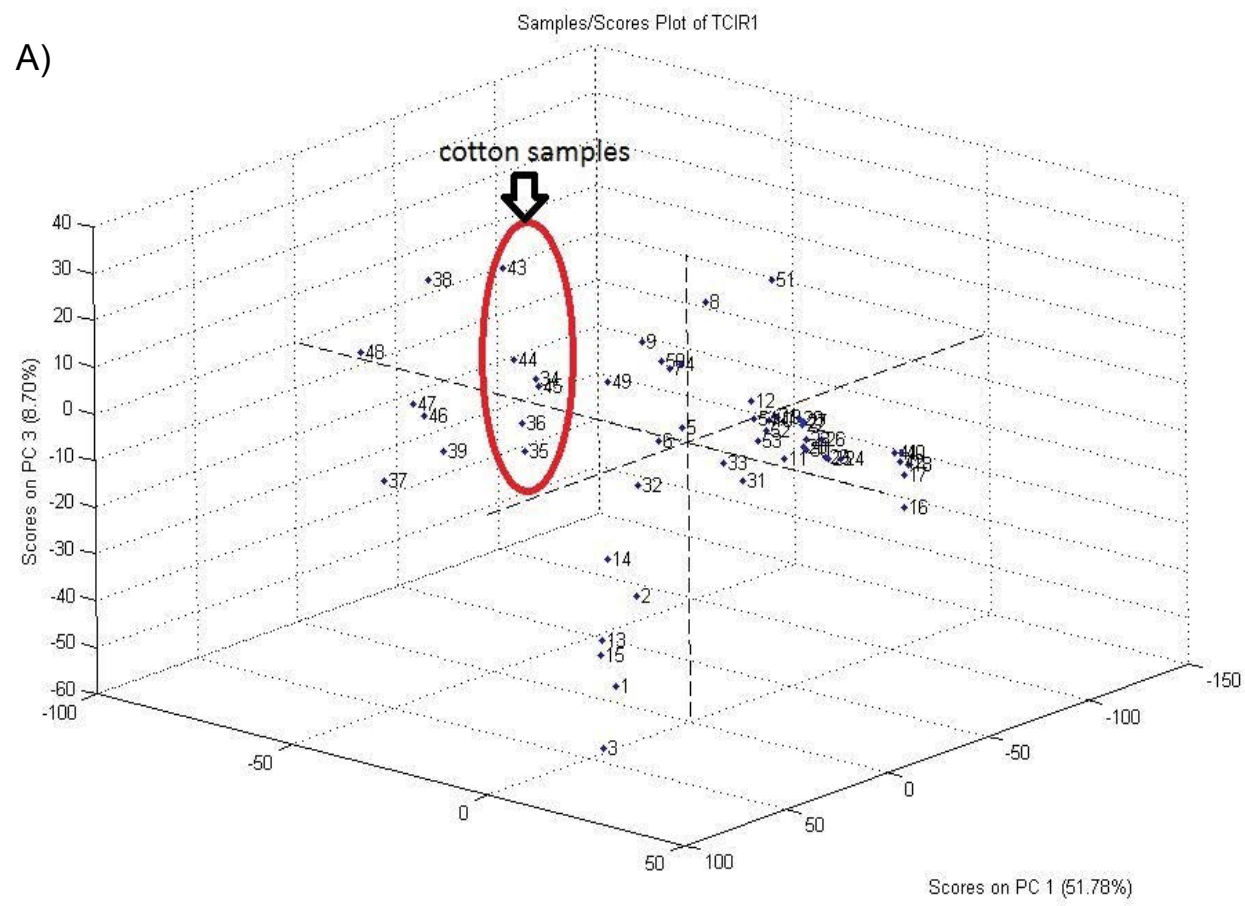

Scores on PC $2(28.15 \%)$

B)

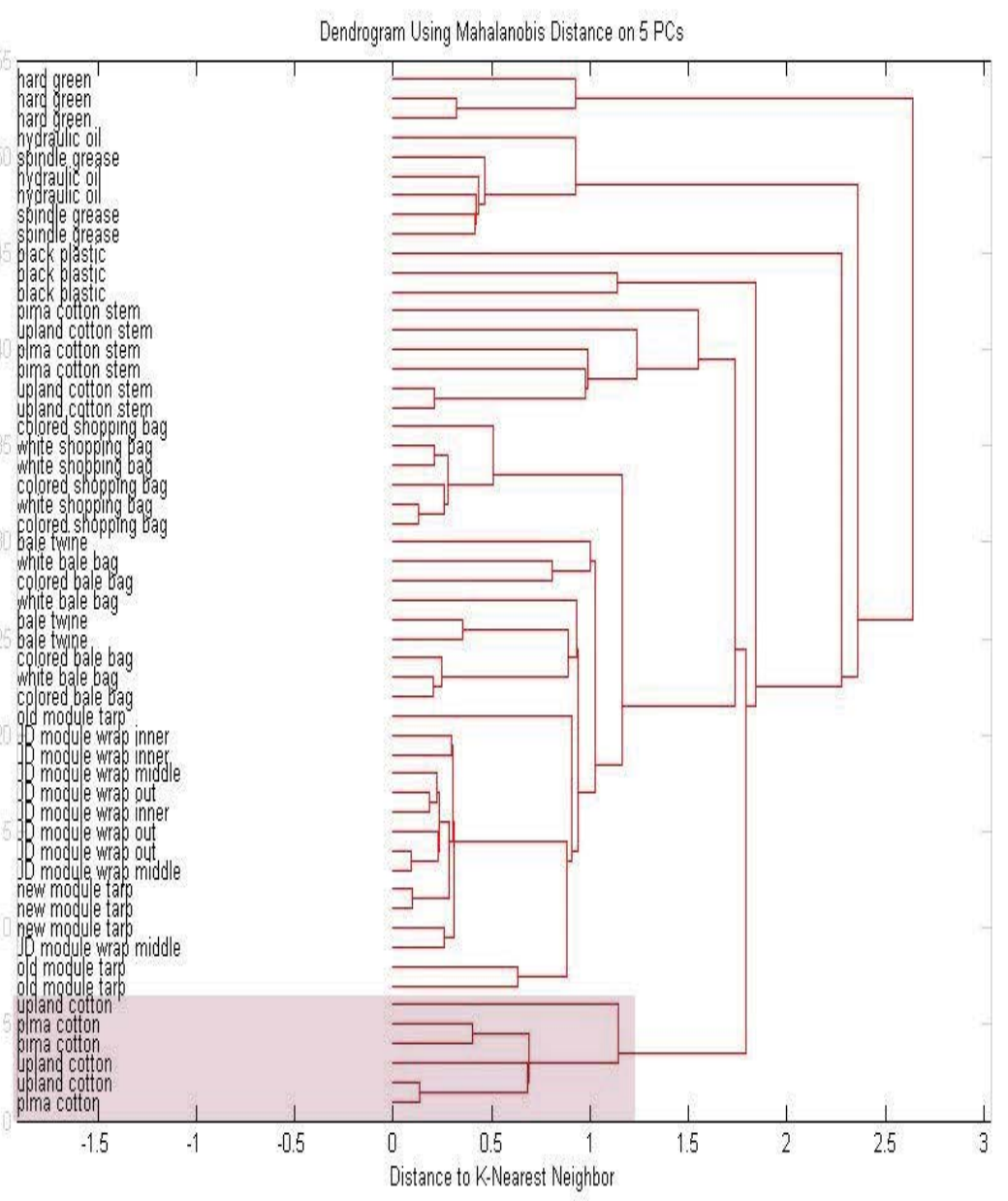

Figure 3: a) PCA scores of FT-IR spectra (i.e., high resolutions) from each sample using the first three principal components (88.69\% of variance). $34,35,36$ and $43,44,45$ are cotton samples.

b) Dendrogram using mahalanobis distance on five principal components for all samples. (I) Materials 13-15 (I), 16-18 and 40-42 (II), 4-6 (III), 37-39 and 46-48 (IV), 1-3, 7-12, and 49-54 (V), 19-33 (VI), and 43-48 (VII). 
Table 2: Transmittance properties for filters used in the instrument (Multi IR Optoelectronics Co, China).

\begin{tabular}{|l|l|l|}
\hline Filter & $\begin{array}{l}\text { Center wavelength (nm) } \\
\text { and bandwidth (FWHM) }\end{array}$ & $\begin{array}{l}\text { Center } \\
\text { wavenumber } \text { (cm }^{-1} \text { ) }\end{array}$ \\
\hline 1 & $6680 \pm 66$ & $1497(1482-1512)$ \\
\hline 2 & $4300 \pm 43$ & $2326(2303-2349)$ \\
\hline 3 & $3400 \pm 30$ & $2941(2915-2967)$ \\
\hline 4 & $3250 \pm 32$ & $3077(3047-3108)$ \\
\hline
\end{tabular}

\section{Simulation}

A simulation was then undertaken to distinguish among the 54 samples (Figure 1 and Table 1) using four wavelength regions. (The $1000 \mathrm{~cm}^{-1}$ was excluded from further studies due to added complexity of light sources and detectors in this spectral region.) Commercially available IR filters (Multi IR optoelectronics, China) were identified for potential use in a low-resolution spectrometer. To determine the feasibility of such bandpass filters for discernment of foreign materials within raw seed cotton, the transmission properties of these filters (Table 2) were used for the generation of simulated low-resolution spectra using data from the higher resolution FT-IR spectrometer.

Transmission measurements using a highresolution FT-IR were then extracted for each filter bandwidth and applied to the corresponding filter transmission profile. The detailed calculation for simulation is in the supplement part (Supplementary Information). The resulting simulated reflectance spectrum for each material was then generated. PCA and subsequent CA were applied to the simulated spectra. The resulting score plot and corresponding cluster analysis dendrogram are shown in Figure $4 a$ and Figure 4b, respectively. PCA results clearly show separation of cotton samples from other materials using three PCs from these low resolution simulated spectra. CA results also reveal simulated cotton samples as grouped in one cluster separated from other materials. The results indicate the potential for successful distinction between cotton and foreign materials using such low-resolution reflectance data. This indicated the feasibility for use of broad-band reflection measurements for discernment of contaminants.

\section{Instrument design and construction}

Figure 5 shows a schematic of the low-resolution IR reflection spectrometer. The incident infrared radiation (Infrared light source model 6580, Newport Corporation, MT) was modulated at 88
$\mathrm{Hz}$ using an optical chopper and focused onto the sample using a $2.5 \mathrm{~cm}$ quartz plano-convex lenses (focal length $5.0 \mathrm{~cm}$ ) with a second $4.0 \mathrm{~cm}$ planoconvex lens (focal length $7.0 \mathrm{~cm}$. The sample holder (constructed in-house) was mounted on a $x, y, z$, $\theta$ stage. The translation stage was used for initial placement of the sample holder and remained constant for the duration of the study. Sample materials were pressed between a movable plate with a $0.65 \mathrm{~cm}$ aperture and a fixed base. The sample holder was blackened using candle soot to minimize background reflection detection. The reflected radiation was then imaged through each band-pass filter (Table 2) using two additional plano-convex quartz lenses $(2.54 \mathrm{~cm}$ diameter with focal lengths 3.81 and $5.0 \mathrm{~cm}$, respectively) onto an IR detector with pre-amplifier (PVMI-2TE1*1-TO8-BaF2, Boston Electronics Corporation, Boston). The detector output was processed with a lock-in amplifier (SR510 lock-in amplifier, Stanford Research, Stanford) referenced to the optical chopper. All optical components were determined to be transparent at each spectral band. specification for the Low-Resolution MidInfrared Reflection Spectrometer.

\section{Data acquisition and analysis}

Initial radiation intensity for each wavelength range $I_{0}$ was measured with no sample present and a neutral diffuse reflecting surface (Aluminum). Each sample was placed behind the aperture and the reflected intensity, I, measured. The reflectance, $R$ was calculated by:

$\mathrm{R}=\mathrm{I} / \mathrm{I}_{0}$

And absorbance then calculated:

Abs $=-\log \left(\mathrm{I} / \mathrm{I}_{0}\right)=-\log (\mathrm{R})$

Each material was analyzed in triplicate and the average value recoded. Support information (S2) shows the averaged absorbance for each sample material and S3 shows the resulting low-resolution absorption spectra for each sample material. A mathematical model was then developed to separate contaminant materials from cotton samples.

\section{Data Analysis Model}

Given a set of data $A=\left(X_{1}, X_{2}, \cdots X n\right)$ all coming from the cotton samples, where each data point is a 4-dimensional real vector, the method used these data to build a standard criterion for classifying the 


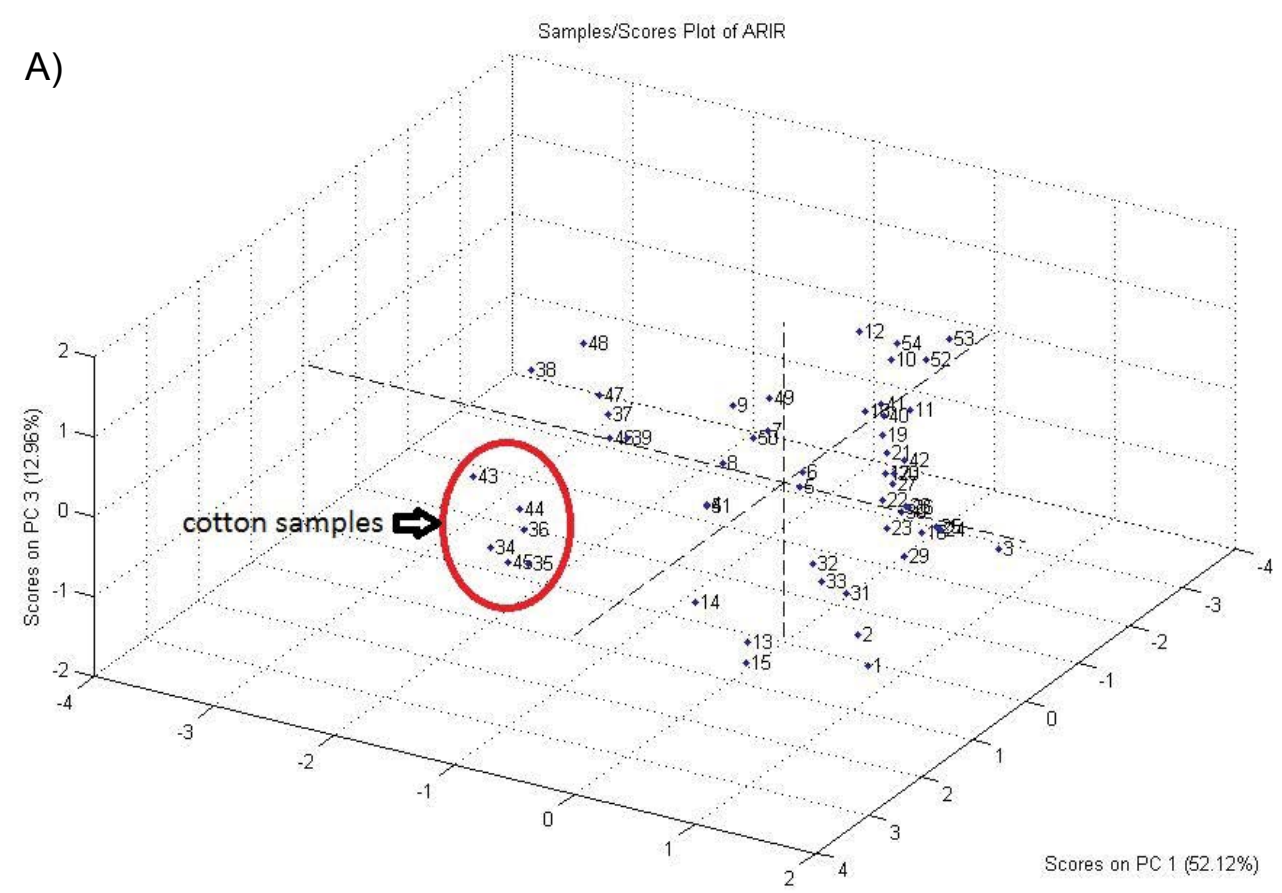

Scores on PC 2 (26.48\%)

B)

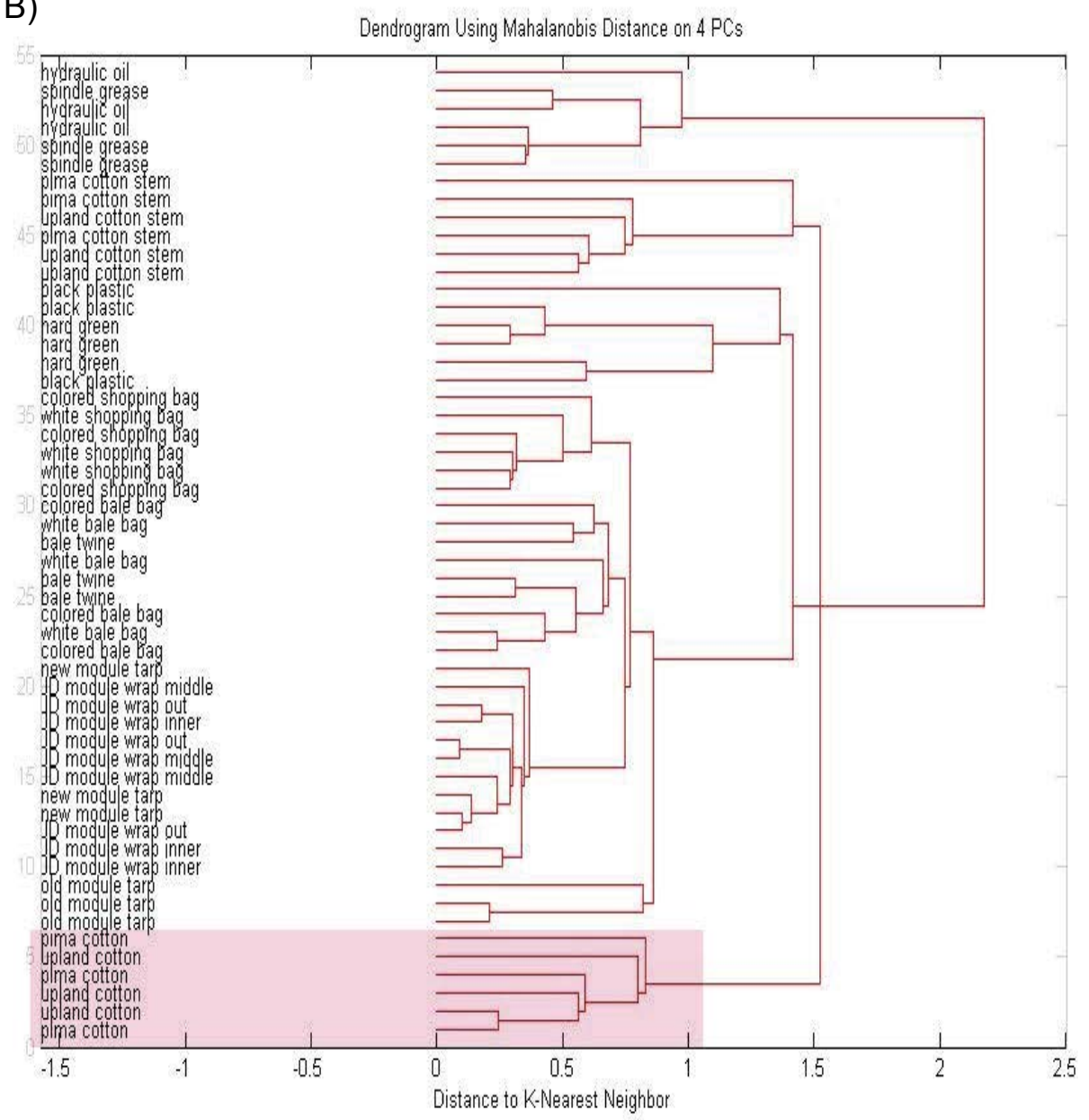

Figure 4: a) PCA scores of simulated, low-resolution spectra from each sample using the first three principal components (91.56\% of variance). 34, 35, 36 and 43, 44, 45 are cotton samples.

b) PCA scores of each sample using the first three principal components ( $91.56 \%$ of variance). $34,35,36$ and 43 , 44, 45 are cotton samples. Regions as indicated in (Figure 2). 


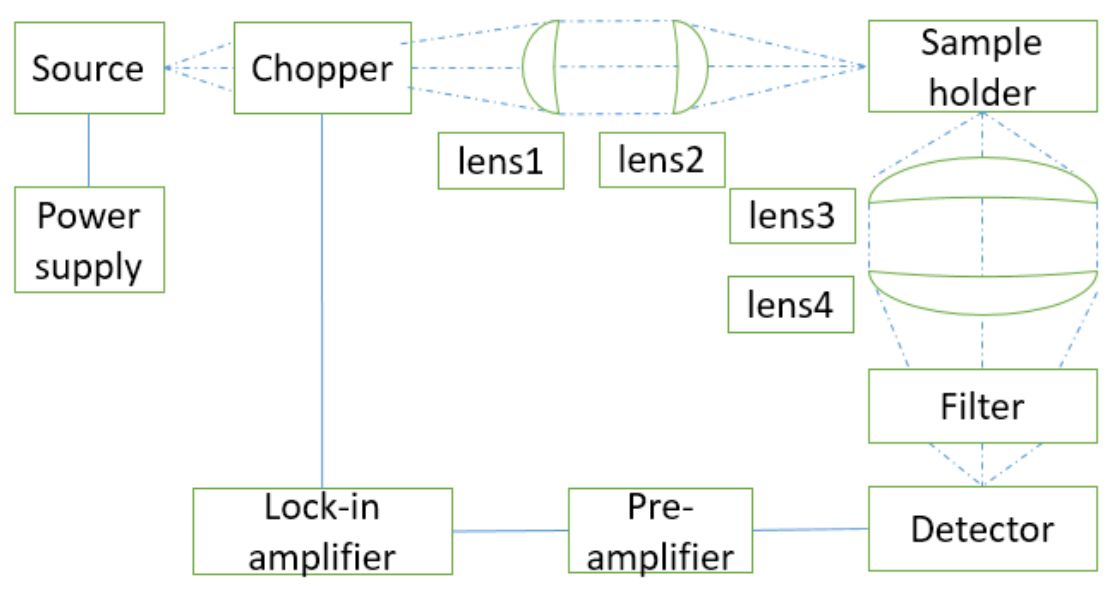

Figure 5: Schematic of the low-resolution IR reflection spectrometer described within the text.

Table 3: The prediction result of the discernment model for all materials (Figure 1) analyzed using the lowresolution mid-infrared reflection spectrometer.

\begin{tabular}{|l|l|l|}
\hline Sample & Actual & Predicted \\
\hline New module tarp & Contaminant & Contaminant \\
\hline Yellow bale bag & Contaminant & Contaminant \\
\hline Color shopping bag & Contaminant & Contaminant \\
\hline JD module outer & Contaminant & Contaminant \\
\hline JD module inner & Contaminant & Contaminant \\
\hline JD module middle & Contaminant & Contaminant \\
\hline White bale bag & Contaminant & Contaminant \\
\hline White shopping bag & Contaminant & Contaminant \\
\hline Bale twine & Contaminant & Contaminant \\
\hline Old module tarp & Contaminant & Contaminant \\
\hline Hard green & Contaminant & Contaminant \\
\hline Black plastic & Contaminant & Contaminant \\
\hline Oil & Contaminant & Contaminant \\
\hline Grease & Contaminant & Contaminant \\
\hline Upland cotton stem & Contaminant & Cotton \\
\hline Pima cotton stem & Contaminant & Cotton \\
\hline Upland cotton & Cotton & Cotton \\
\hline Upland cotton & Cotton & Cotton \\
\hline
\end{tabular}

new observation. The centroid of the cluster $A$ is defined as

$$
C=\frac{1}{n} \sum_{i=1}^{n} X_{i}
$$

and the distance between the data $X_{i}$ and $\mathrm{C}$ was calculated by Euclidean distance:

$$
d_{i}=\left(\sum_{j=1}^{4}\left(X_{i j}-C_{j}\right)^{2}\right)^{\frac{1}{2}}, \text { for } i=1,2, \Lambda n .
$$

When the distance between the centroid and the new observation point was greater than $d$, the new observation point was treated as a contaminant.
If less than or equal to $d$, it was considered to be cotton, where

$$
d=\max _{i}\left\{d_{1}, d_{2} \ldots, d_{n}\right\}+\varepsilon \text {, the error } \varepsilon \text { was }
$$
set to $1.0 \times 10^{-4}$.

The program using this model was written in the Matlab (Mathworks, version 2013a, Natick, MA). Data from 30 cotton samples were used as standard samples. The spectra additional samples were then applied to this model. The results are shown in Table 3.

Using this discernment model, only upland cotton stem and pima cotton stem samples were not successfully distinguished from cotton materials. This corresponds to a misclassification rate of only $11.1 \%$. Because these were each pure material samples, a set of samples with varied amounts of contaminant within the sample window with a cotton background were generated and tested.

New module tarp sample was used to exemplify the calculated detectability. The model was used to determine if a sample was cotton or a contaminant. Image analysis software (ImageJ $1.49 \mathrm{v}$, National Institute of Health, US Department of Health and Human Services, Bethesda, MD) was used to calculate the area percentage of contaminant on a cotton sample. As indicated above, the aperture diameter in the sample holder plate was $6.5 \mathrm{~mm}$ (an area of $33.2 \mathrm{~mm}^{2}$ ). The instrument correctly classified the new module tarp sample as not cotton when it covered $43.2 \%\left(14.3 \mathrm{~mm}^{2}\right)$ of the sample holder aperture with a cotton background, Figure 5a. The instrument misclassified the sample when it covered $31.2 \%\left(10.4 \mathrm{~mm}^{2}\right)$ or less of the field of view, Figure $5 \mathrm{~b}$. So, the detectability for 
Table 4: The detect limit of each sample (Figure 1) using the Low-resolution mid-infrared reflection spectrometer $(\mathrm{S} / \mathrm{N}=3)$.

\begin{tabular}{|l|l|l|}
\hline Sample & Detectability & \\
\hline New module tarp & Percentage of the field of view & Area $\mathbf{m m}^{\mathbf{2}} \mathbf{~}$ \\
\hline Yellow bale bag & $43.2 \%-31.2 \%$ & $14.3-10.4$ \\
\hline Color shopping bag & $49.0 \%-36.0 \%$ & $16.3-12.0$ \\
\hline JD module out & $46.3 \%-31.4 \%$ & $15.4-10.4$ \\
\hline JD module inner & $39.8 \%-28.4 \%$ & $13.2-9.4$ \\
\hline JD module middle & $42 \%-32.7 \%$ & $14.0-10.9$ \\
\hline White bale bag & $32.2 \%-25.6 \%$ & $10.7-8.5$ \\
\hline White shopping bag & $50.6 \%-40.7 \%$ & $16.8-13.5$ \\
\hline Bale twine & $48.4 \%-32.2 \%$ & $16.1-10.7$ \\
\hline Old module tarp & $55.7 \%-39.9 \%$ & $18.5-13.3$ \\
\hline Hard green & $39.7 \%-24.2 \%$ & $13.2-8.0$ \\
\hline Black plastic & $60.7 \%-26.5 \%$ & $20.1-8.8$ \\
\hline Oil & $31.4 \%-11.7 \%$ & $10.4-3.9$ \\
\hline Grease & $58.9 \%-33.5 \%$ & $19.6-11.1$ \\
\hline
\end{tabular}
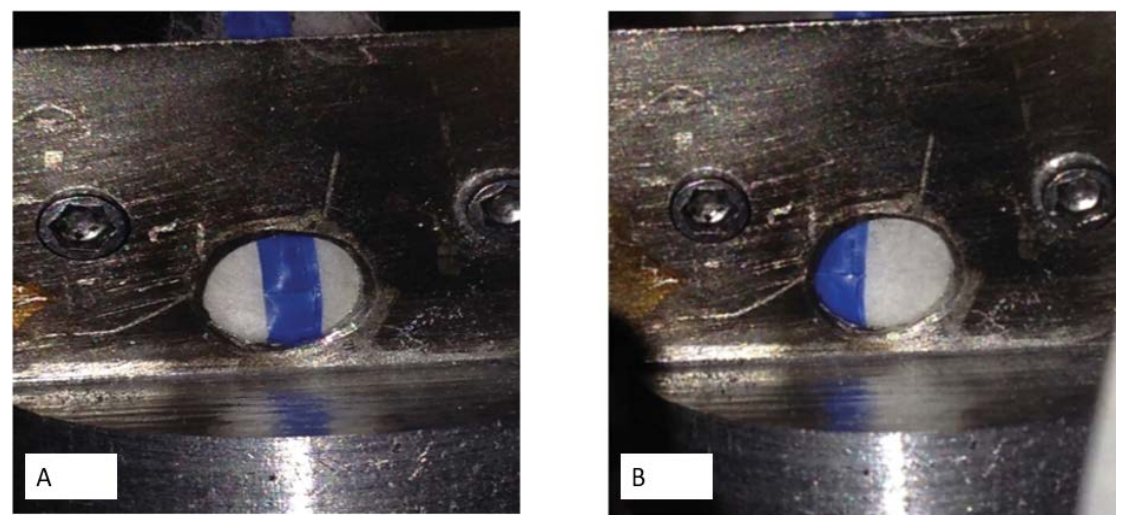

Figure 6: a) The instrument classified the sample as not cotton when it covered $43.2 \%\left(14.3 \mathrm{~mm}^{2}\right)$ of the aperture with a cotton background; b) The instrument misclassified the sample when it covered $31.2 \%\left(10.4 \mathrm{~mm}^{2}\right)$.

new module tarp is reported as between $43.2 \%$ $31.2 \%\left(14.3-10.4 \mathrm{~mm}^{2}\right)$.

\section{Detection limits}

The detection limit of the instrument for each material was then calculated as the sampled area that resulted in a reflectance measurement that was three times larger than the standard deviation of the blank, i.e., $\mathrm{S} / \mathrm{N}=3$. These limits of detection are listed in Table 4. Again, detectability was defined as the percentage of the field of view for the reflection measurement that contained the contaminant and resulted in a positive discernment of the contaminate. The remaining portion of the viewing area for each measurement consisted of pure cotton (Figure 6). Listed are the percentages of the viewing area containing the contaminant that resulted in positive discernment of its presence (as indicted in Figure 6). This was relative to the signal from only cotton.

\section{Conclusion}

In this study, a low resolution mid-infrared reflection instrument was designed and constructed for discernment of contaminants in seed cotton. This reflection instrument used only four IR filters with transmittance centered at 3100, 2900, 2300, and $1500 \mathrm{~cm}^{-1}$ to achieve the discernment of cotton samples from 16 contaminants (such as plastic and grease). These four spectral bands were determined from a high-resolution FT-IR spectra data base for all the samples (cotton and contaminants) using statistical tools (PCA, CA, and MCR). The instrument correctly differentiated contaminants from cotton with $100 \%$ accuracy as pure materials. When the contaminants were placed on a cotton background, 
the detection limit for all samples ranged from $60 \%$ to $11 \%$ of the field of view. The described instrument has significantly lower cost and time required for the task compared to use of a highresolution FT-IR spectrometer. More importantly, it has potential for application to gin facilities to separate contaminants from cotton in real time. This would dramatically improve its quality and textile utility of processed seed cotton.

\section{Conflict of Interest}

The authors report there is no conflict of interest.

\section{Funding}

This research was supported by Cotton Incorporated.

\section{References}

1. Lewin M, Pearce EM (1998) Handbook of fiber chemistry. CRC Press.

2. Allen A, Jonn F, Gary G (2007) Textile technology preliminary fourier-transform infrared spectroscopy analysis of cotton trash. The Journal of Cotton Science 11: 68-74.

3. Fortier C, Rodgers J, Foulk J (2011) Investigation of the impact of instrumental and software applications on cotton and botanical trash identification by ultraviolet-visible and near-infrared spectroscopy. J Cotton Sci 15: 170-178.

4. Liu Y, Thibodeaux D (2013) Feasibility of visible and near infrared spectroscopy in the determination of cotton trash components. J Cotton Sci 17: 195-201.

5. Fortier CA, James ER, Michael SC, Xiaoliang C, Jonn AF (2011) Identification of cotton and cotton trash components by fourier transform near-infrared spectroscopy. Textile Research Journal 81: 230-238.

6. Fortier C, James R, Jonn F, Derek W (2012) Nearinfrared classification of cotton lint, botanical and field trash. Journal of Cotton Science 16: 72-79.

7. Jiang Y, Changying LI (2014) A push-broom based hyperspectral imaging system for cotton trash identification. American Society of Agricultural and Biological Engineers.

8. Fortier C (2012) Fourier transform spectroscopy of cotton and cotton trash. INTECH Open Access Publisher.

9. DS Himmelsbach, JW Hellgeth, DD McAlister (2006) Development and use of an attenuated total reflectance/fourier transform infrared (ATR/FTIR) spectral database to identify foreign matter in cotton. J Agric Food Chem 54: 7405-7412.

10. Foulk J, David McAlister, David Himmelsbach, Ed Hughs (2004) Textile technology mid-infrared spectroscopy of trash in cotton rotor dust. J Cotton Sci 8: 243-253.

11. C Chung, M Lee, EK Choe (2004) Characterization of cotton fabric scouring by FT-IR ATR spectroscopy. Carbohydrate Poly 58: 417-420.

12. Liu Y, Gamble GR, Thibodeaux D (2010) Assessment of recovered cotton fibre and trash contents in lint cotton waste by ultraviolet/visible/near infrared reflectance spectroscopy. J Near Infrared Spectrosc 18: 239.

13. Ruckebusch C, Blanchet $L$ (2013) Multivariate curve resolution: A review of advanced and tailored applications and challenges. Anal Chim Acta 765: 28-36.

14. Lavine BK (2000) Chemometrics. Anal Chem 72: 91-98. 


\section{Supplement Information}

Calculation of simulated low-resolution reflectance measurement from higher-resolution data.

For example, intensity $I_{0}$ at 6680 was defined as 100 after passing through the filter.

$I_{0}$ at other wavelengths (6746-6616 nm) can then be calculated by $I_{0}=f^{*} 100$, where $f$ is the ratio from filter transmission profile.

$\mathrm{I}_{\mathrm{Ot}}$ total for the filter was simply the integrated intensities using

$$
I_{0 t}=\sum_{6616}^{6746} I_{0}
$$

Subsequently, $I_{1}$ (the intensity after reflected by the sample) at each wavelength was calculated as $\mathrm{I}_{1}=\mathrm{I}_{0}{ }^{*} \mathrm{~T}$, where $\mathrm{T}$ is the transmittance from the highresolution FT-IR spectrum. $\mathrm{I}_{1 \mathrm{t}}$ total for the filter was calculated in a similar manner using

$$
I_{1 t}=\sum_{6616}^{6746} I_{1}
$$

Finally, simulated reflectance, $R$, for the filter were calculated from $R=I_{1 t} / I_{0 t}$

Using an upland cotton sample and the 6680 \pm 66 (6746-6614 nm) filter sample calculation, the intensity of the incident light at $6680 \mathrm{~nm}$ was defined as 100 units and that of light outside of the filter transmission range (6614-6746 nm) was set to zeros. Within this range, the incident intensity was calculated in $4.4 \mathrm{~nm}$ increments (same resolution as for the FT-IR spectrometer). From $6614 \mathrm{~nm}$ to $6680 \mathrm{~nm}$, the equation becomes

$$
I_{0}(\lambda i)=\frac{100}{66}(\lambda i-6614)
$$

Where $\lambda i$ is the wavelength. Hence, from 6680 $\mathrm{nm}$ to $6746 \mathrm{~nm}$, the equation

$$
I_{0}(\lambda i)=-\frac{100}{66}(\lambda i-6680)+100
$$

was then used. The resulting intensity for each wavelength is shown in Supplementary Table 1.

The total $\mathrm{I}_{0}$ for this filter is then:

$$
I_{0 t}=\sum_{6616}^{6746} I_{0}(\lambda i)=1500.00
$$

The individual reflectance for this wavelength range with an upland cotton sample from FT-IR spectrum is listed in Supplementary Table 2.

$I_{1}$ (The simulated intensity of the reflected radiation) at each wavelength was then calculated using $I_{1}=I_{0}{ }^{*} R$

The resulting values of $I_{1}$ are shown in Supplementary Table 3.

The calculated total reflected radiation for the filter was calculated using

$$
I_{1 t}=\sum_{6616}^{6746} I_{1}=1352.1
$$

And the simulated reflectance $(R)$ for the 6680 $\mathrm{nm}$ filter was then, $\mathrm{R}=\mathrm{I}_{1 \mathrm{t}} / \mathrm{I}_{0 \mathrm{t}}=90.14 \%$.

Similar calculations were undertaken for each filter. The resulting simulated reflectance spectrum for each material was then generated. Representatives of those are shown in Supplementary Figure 1, Supplementary Figure 2 and Supplementary Table 4.

Supplementary Table 1: I for each wavelength from 6614-6746 nm.

\begin{tabular}{|l|l|l|l|l|l|l|l|l|}
\hline Wavelength & 6614 & 6618.4 & 6622.8 & 6627.2 & 6631.6 & 6636 & 6640.4 & 6644.8 \\
\hline$I_{0}$ & 0 & 6.67 & 13.33 & 20 & 26.67 & 33.33 & 40 & 46.67 \\
\hline Wavelength & 6649.2 & 6653.6 & 6658 & 6662.4 & 6666.8 & 6671.2 & 6675.6 & 6680 \\
\hline$I_{0}$ & 53.33 & 60 & 66.67 & 73.33 & 80 & 86.67 & 93.33 & 100 \\
\hline Wavelength & 6684.4 & 6688.8 & 6693.2 & 6697.6 & 6702 & 6706.4 & 6710.8 & 6715.2 \\
\hline$I_{0}$ & 93.33 & 86.67 & 80 & 73.33 & 66.67 & 60 & 53.33 & 46.67 \\
\hline Wavelength & 6719.6 & 6724 & 6728.4 & 6732.8 & 6737.2 & 6741.6 & 6746 \\
\hline$I_{0}$ & 40 & 33.33 & 26.67 & 20 & 13.33 & 6.67 & 0 & \\
\hline
\end{tabular}




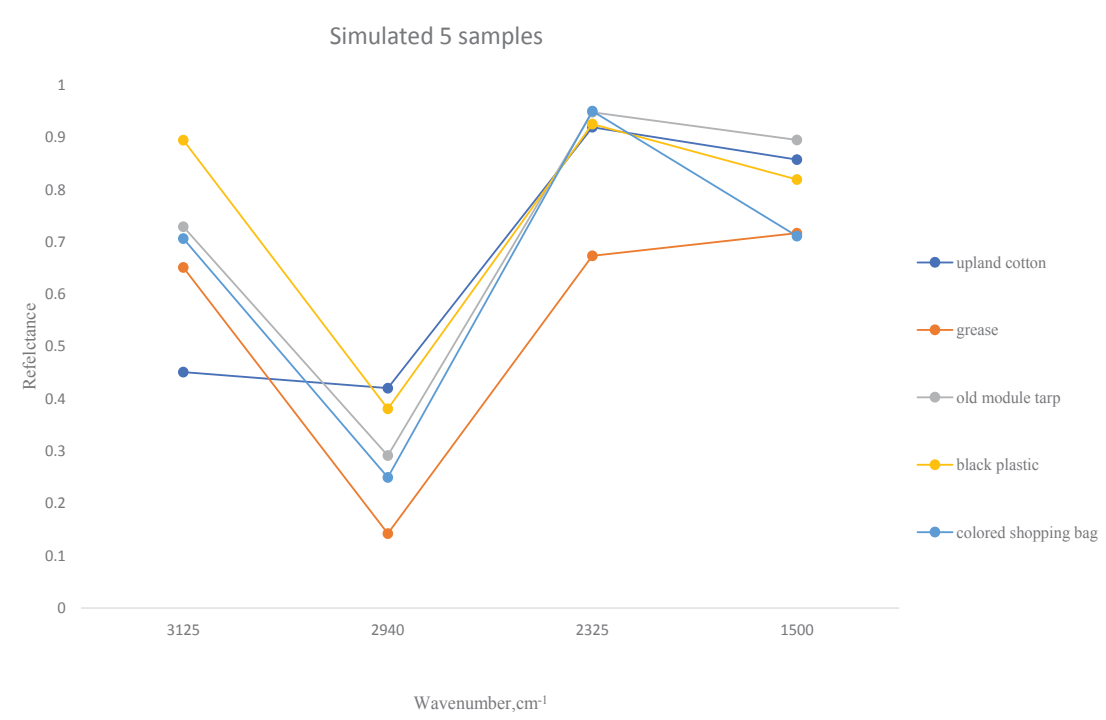

Supplementary Figure 1: Simulated transmittance spectra for upland cotton, grease, old module tarp, black plastic and colored shopping bag.

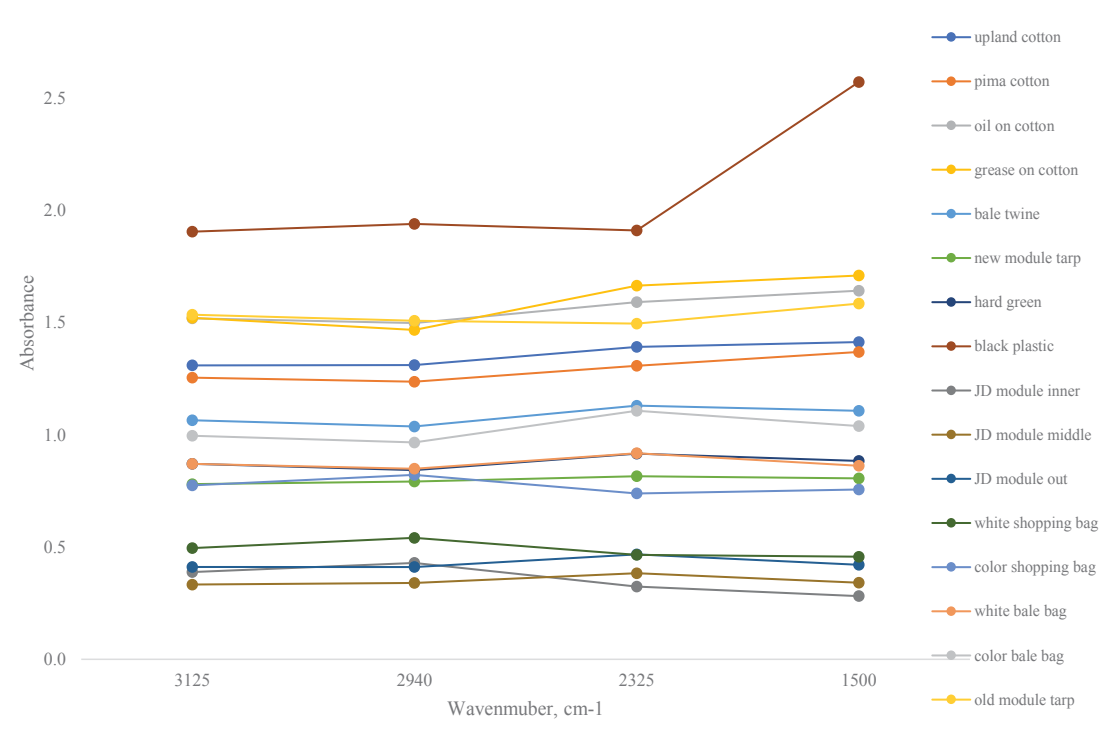

Supplementary Figure 2: Average absorbance plot for each sample from the Low-resolution mid-infrared reflection spectrometer.

Supplementary Table 2: Reflectance (R) for $6614 \mathrm{~nm}$ to $6746 \mathrm{~nm}$ from high resolution FT-IR spectrum.

\begin{tabular}{|l|l|l|l|l|l|l|l|l|}
\hline Wavelength & 6614 & 6618.4 & 6622.8 & 6627.2 & 6631.6 & 6636 & 6640.4 & 6644.8 \\
\hline $\mathbf{R}$ & 0.877 & 0.877 & 0.878 & 0.88 & 0.883 & 0.885 & 0.887 & 0.887 \\
\hline Wavelength & 6649.2 & 6653.6 & 6658 & 6662.4 & 6666.8 & 6671.2 & 6675.6 & 6680 \\
\hline $\mathbf{R}$ & 0.89 & 0.891 & 0.893 & 0.895 & 0.896 & 0.898 & 0.9 & 0.901 \\
\hline Wavelength & 6684.4 & 6688.8 & 6693.2 & 6697.6 & 6702 & 6706.4 & 6710.8 & 6715.2 \\
\hline R & 0.903 & 0.905 & 0.907 & 0.908 & 0.91 & 0.912 & 0.913 & 0.915 \\
\hline Wavelength & 6719.6 & 6724 & 6728.4 & 6732.8 & 6737.2 & 6741.6 & 6746 & \\
\hline R & 0.917 & 0.918 & 0.92 & 0.922 & 0.923 & 0.925 & 0.927 & \\
\hline
\end{tabular}


Supplementary Table 3: $I_{1}$ (The intensity after $I_{0}$ reflected from upland cotton sample) at each wavelength (nm).

\begin{tabular}{|l|l|l|l|l|l|l|l|l|}
\hline Wavelength & 6614 & 6618.4 & 6622.8 & 6627.2 & 6631.6 & 6636 & 6640.4 & 6644.8 \\
\hline$I_{1}$ & 0 & 5.85 & 11.7 & 17.6 & 23.55 & 29.5 & 35.48 & 41.4 \\
\hline Wavelength & 6649.2 & 6653.6 & 6658 & 6662.4 & 6666.8 & 6671.2 & 6675.6 & 6680 \\
\hline$I_{1}$ & 47.46 & 53.46 & 59.54 & 65.63 & 71.68 & 77.83 & 84 & 90.1 \\
\hline Wavelength & 6684.4 & 6688.8 & 6693.2 & 6697.6 & 6702 & 6706.4 & 6710.8 & 6715.2 \\
\hline$I_{1}$ & 84.28 & 78.44 & 72.56 & 66.58 & 60.67 & 54.72 & 48.69 & 42.7 \\
\hline Wavelength & 6719.6 & 6724 & 6728.4 & 6732.8 & 6737.2 & 6741.6 & 6746 & \\
\hline$I_{1}$ & 36.68 & 30.6 & 24.54 & 18.44 & 12.3 & 6.17 & 0 & \\
\hline
\end{tabular}

Supplementary Table 4: Average absorbance of each sample from the low-resolution mid-infrared reflection spectrometer.

\begin{tabular}{|l|l|l|l|l|}
\hline Abs average & $\mathbf{1}$ & $\mathbf{2}$ & $\mathbf{3}$ & $\mathbf{4}$ \\
\hline Upland cotton & 1.31 & 1.31 & 1.39 & 1.41 \\
\hline Pima cotton & 1.26 & 1.24 & 1.31 & 1.37 \\
\hline Oil on cotton & 1.52 & 1.5 & 1.59 & 1.64 \\
\hline Grease on cotton & 1.52 & 1.47 & 1.67 & 1.71 \\
\hline Bale twine & 1.06 & 1.04 & 1.13 & 1.11 \\
\hline New module tarp & 0.78 & 0.79 & 0.82 & 0.81 \\
\hline Old module tarp & 1.54 & 1.51 & 1.5 & 1.59 \\
\hline Hard green & 0.87 & 0.84 & 0.92 & 0.88 \\
\hline Black plastic & 1.91 & 1.94 & 1.91 & 2.57 \\
\hline JD module inner & 0.39 & 0.43 & 0.32 & 0.28 \\
\hline JD module middle & 0.33 & 0.34 & 0.38 & 0.34 \\
\hline JD module outer & 0.41 & 0.41 & 0.47 & 0.42 \\
\hline White shopping bag & 0.5 & 0.54 & 0.47 & 0.46 \\
\hline Color shopping bag & 0.78 & 0.82 & 0.74 & 0.76 \\
\hline White bale bag & 0.87 & 0.85 & 0.92 & 0.86 \\
\hline Color bale bag & 1 & 0.97 & 1.11 & 1.04 \\
\hline
\end{tabular}

